International Journal of Current Advanced Research

ISSN: O: 2319-6475, ISSN: P: 2319 - 6505, Impact Factor: SJIF: 5.995

Available Online at www.journalijcar.org

Volume 6; Issue 5; May 2017; Page No. 3713-3715

DOI: http://dx.doi.org/10.24327/ijcar.2017.3715.0352

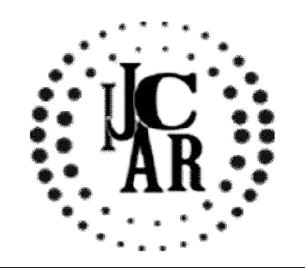

Research Article

\title{
A STUDY OF URETERIC STRICTURE IN GENITOURINARY TUBER-CULOSIS
}

\author{
Rajesh KMㄹ., Saravanan $K^{2}$., Jayaganesh $\mathbf{R}^{3}$ and Ezhilsundher $\mathbf{V}^{4}$
}

Govt Kilpauk Medical College/Govt Royapettah Hospital, Chennai

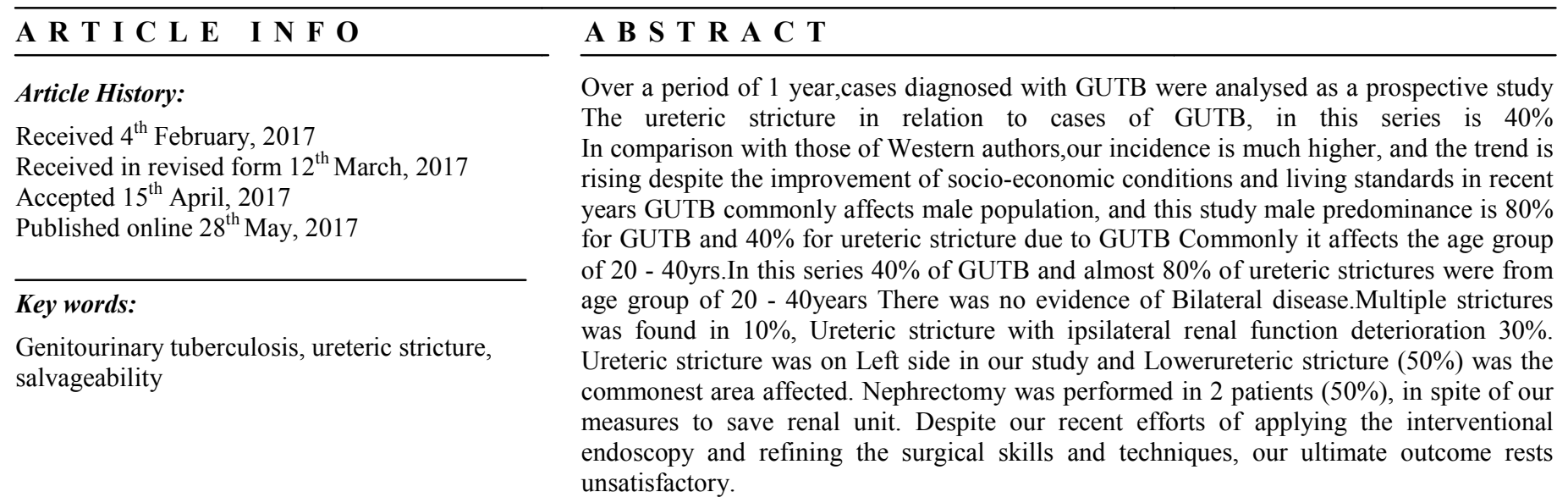

Copyright $₫ 2017$ Rajesh KM et al. This is an open access article distributed under the Creative Commons Attribution License, which permits unrestricted use, distribution, and reproduction in any medium, provided the original work is properly cited.

\section{INTRODUCTION}

Tuberculosis (TB) remains a worldwide scourge, with significant mortality and morbidity both in developing and developed nations. Most of the infection occurs in the economically productive age group. Poverty associated with poor nutrition and crowded living conditions represent the risk factors for the development of Tuberculosis. Nearly 15 $20 \%$ of all new cases of Tuberculosis involve sites outside of the lung, and approximately $30 \%$ of cases of extra pulmonary Tuberculosis involve Genitourinary Tract, therefore Genitourinary Tuberculosis (GUTB) makes approximately $5 \%$ of all cases of $\mathrm{TB}(1)(2)$. Diffuse hematogenous dissemination occurs at time of initial pulmonary infection in approximately $25 \%$ of pulmonary cases. Ureteral involvement, which is rarely found in absence of more severe renal changes, mucosal nodules and ulceration occur with thickening of ureteral wall, fibrosis and even calcification.Renal damage secondary to ureteral strictures may be more severe than the effect of original parenchymal involvement(3). The fibrosis causing the strictures represents healing of tuberculous ulcerations, and this may develop during appropriate chemotherapy. Early scarring may be reversible by steroids therapy, but end-stage fibrotic strictures are irreversible (4). Dilatation and stenting of ureteral stricture may regain/retain ureteral patency and salvage kidney

*Corresponding author: Rajesh KM.

Govt Kilpauk Medical College/Govt Royapettah Hospital, Chennai function but ureteral dynamics are often compromised (5) (6). Hence the study of ureteric stricture due to GUTB may throw a light into this complex problem and better understanding of disease and management.

\section{Aim}

1. To estimate the prevalence of ureteric involvement in GUTB in the population served in the hospital

2. To discuss the various modes of presentations of ureteric involvement in GUTB

3. To determine the significance of relevant laboratory investigations in diagnosis

4. To compare the efficacy of various therapeutic modalities adapted

5. To assess the impact on mortality and morbidity of GUTB

6. To draw diagnostic and therapeutic protocols for systematic approach towards a case of ureteric tuberculosis

\section{MATERIALS AND METHODS}

Over a period of 1 year from June 2015 to July 2016 in our Department of Urology, Government Royapettah Hospital and Kilpauk Medical College and Hospital, we have received and treated 10 cases of GUTB.

Patients suspected to have GUTB were investigated with following investigations

\section{Hematocrit}


2. Total and Differential WBC count

3. ESR

4. Urine investigations like albumin,sugar and deposits

5. Three days preferably five early morning Urine for AFB-smear and culture

6. Renal parameters

7. Ultrasound KUB

8. Intravenous Urogram

9. X-ray chest

10. Cystoscopy, biopsy if necessary

11. Antegrade studies in relevant cases

\section{Patients diagnosed with GUTB were analysed into}

1. Percentage of patients with ureteric involvement

2. Male,Female sex ratio

3. Presentation in various age group

4. Various modes of clinical presentation

5. Investigations

6. Level of stricture involvement in ureter

7. Urgent treatments like DJ stenting or PCN

8. Medical management alone

9. Medical management with various surgical management

10. Role of our management in salvaging the kidney function

Patients were classified into those presenting with Obstructive Uropathy and without Obstruction.Those presenting with bladder involvement without obstructive uropathy were investigated and Antituberculous treatment (ATT) started. During Cystoscopy random bladder biopsy was taken and sent for Histopathological Examination (HPE)

Patients presenting with Obstructive uropathy with Functioning renal parenchyma were submitted for Cystoscopy under anaesthesia and DJ stenting was attempted on affected side.If stenting was done, patient continued with ATT and DJ stent changed once in 3months

After 6 months DJ stent removed and IVU done to assess Renal function and Obstruction. If function normal, patient followed regularly. If there is obstruction DJ stenting was done again.

If stenting was not possible, percutaneous nephrostomy was performed.PCN fluid was analysed including the volume and qualitative analysis.If the kidney was salvageable, surgical procedures like Ureteroneocystostomy or Boari's flap were done

If kidney is poorly functioning Nephroureterectmy was done.If there is lower ureteric stricture associated with reduced bladder capacity, Augmentation cystoplasty with Ureteric reimplantation into bowel segment was done

\section{Observation}

In this prospective study, over a period of one year June 2015

- July 2016, cases diagnosed as GUTB were analysed

Total number of cases of GUTB - 10

Ureteric stricture cases in GUTB -4

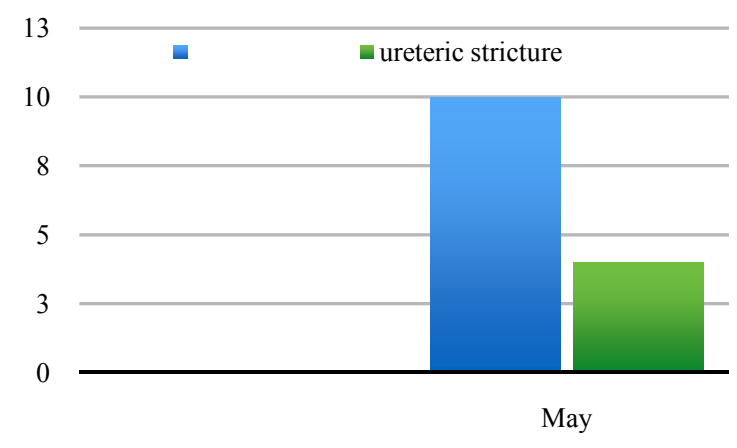

Sex Difference

Genitourinary Tuberculosis

\begin{tabular}{ccc}
\hline & Gutb & Ureteric stricture \\
\hline Male & 8 & 3 \\
Female & 2 & 1 \\
\hline
\end{tabular}

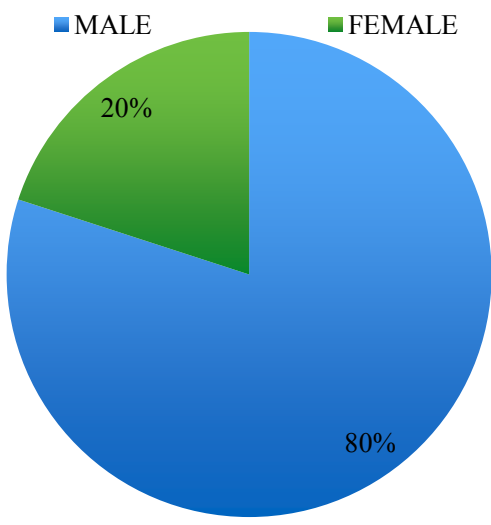

Age Distribution

\begin{tabular}{ccc}
\hline Age in years & $\begin{array}{c}\text { Genitourinary } \\
\text { tuberculosis }\end{array}$ & Ureteric stricture \\
\hline $20-30$ Yrs & 2 & 1 \\
$31-40$ Yrs & 2 & 2 \\
$41-50$ Yrs & 3 & 1 \\
$51-60$ Yrs & 1 & \\
\hline
\end{tabular}

\section{Clinical Presentation}

1. Loin pain - 2 patients

2. LUTS - 4 patients

3. Raised renal parameters -3 patients

4. Presented with features of ureteric stone - 1patient

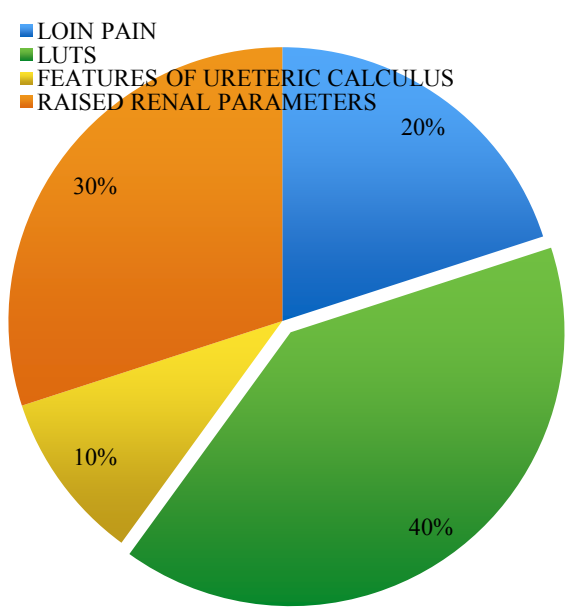




\section{Investigations}

\begin{tabular}{cc}
\hline Investigation & $\begin{array}{c}\text { NO. OF } \\
\text { Cases }\end{array}$ \\
\hline Urine for afb smear & 3 \\
Diagnosed by bladder biopsy & 1 \\
Post operative diagnosis by biopsy & 1 \\
Empirical diagnosis & 5 \\
\hline
\end{tabular}

\section{Ureteric Stricture - Side}

Total number of patients with ureteric stricture - 4

Unilateral strictures (Left) -4

\section{Ureteric Stricture - Site}

Lower ureteric stricture - 2

Mid ureteric stricture - 1

Proximal ureteric stricture - 1

Ureteric Stricture With Ipsilateral Renal Function

Deterioration - 3 patients

\section{Management}

Surgery - 3 patients

Conservative management - 1 patient

Primary surgery - 1 patient

Surgery following DJ stenting - 1patient

Surgery following PCN - 2patients

\section{Surgical Procedures}

Nephrectomy - 2

Augmentation cystoplasty with ureteric reimplantation - 1

Pyeloureterostomy - 1

\section{Primary surgery}

\section{Nephrectomy}

Nephrectomy was performed for 1 patient - diagnosed preoperatively as Nonfunctioning unit due to Tuberculosis and underwent Nephrectomy after 6 weeks course of ATT.

\section{Surgery Following Dj Stenting}

Primary DJ stenting was performed and ATT given for 6months

After stent removal there was evidence of Lower ureteric stricture and Reduced bladder capacity. So Augmentation cystoplasty with Ureteric Reimplantation was done

\section{Surgery Following Pcn}

PCN was performed for 2 patients with ureteric obstruction where DJ stenting couldn't be performed. For one patient PCN wasn't draining adequately because of poor function and hence Nephrectomy was performed.
One patient had mid ureteric stricture, DJ stenting failed so PCN was done.Antegrade Nephrostogram revealed mid ureteric stricture, so ureterouretrostomy was done with DJ stent placement. Post op RGP after three weeks demonstrated good anastomosis and no evidence of extravasation and good drainage of contrast.

\section{DISCUSSION}

Over a period of 1 year, cases diagnosed with GUTB were analysed as a prospective study. The ureteric stricture in relation to cases of GUTB, in this series is $40 \%$ In comparison with those of Western authors, our incidence is much higher, and the trend is rising despite the improvement of socioeconomic conditions and living standards in recent years GUTB commonly affects male population, and this study male predominance is $80 \%$ for GUTB and $40 \%$ for ureteric stricture due to GUTB Commonly it affects the age group of 20 - 40yrs. In this series $40 \%$ of GUTB and almost $80 \%$ of ureteric strictures were from age group of 20 - 40years there was no evidence of Bilateral disease. Multiple strictures was found in $10 \%$, Ureteric stricture with ipsilateral renal function deterioration $30 \%$.

Ureteric stricture was on Left side in our study and Lower ureteric stricture $(50 \%)$ was the commonest area affected. Nephrectomy was performed in 2 patients $(50 \%)$, in spite of our measures to save renal unit.

Despite our recent efforts of applying the interventional endoscopy and refining the surgical skills and techniques, our ultimate outcome rests unsatisfactory.

\section{References}

1. Goel A, Seth A, Kumar R. Autocystectomy following extensive genitourinary tuberculosis: Presentation and management. IntUrolnephrol 2002;34:325-7

2. Kennedy DH : Extrapulmonary tuberculosis .In: The Biology of Mycobacteria, Vol. III, edited by Ratledge C, Stanford JL, Grange JM, Newyork, Academic Press, 1989, pp 245-284

3. Jung YY, Kim JK, Cho KS. Genitourinary tuberculosis: Comprehensive cross-sectional imaging. AJR Am J Roentgenol 2005;184:143-50

4. Kim SH. Urogenital tuberculosis. In: Pollack HM, McClennan BL, editors. Clinical Urography. 2nd ed. Philadelphia, PA: WB Saunders Co; 2000. p. 11931228

5. Wang LJ, Wu CF, Wong YC, Chuang CK, Chu SH, Chen CJ. Imaging findings of urinary tuberculosis on excretory urography and computerised tomography. J Urol 2003;169:524-8

6. Harisinghani MG, Mcloud TC, Shepard JA, Ko JP, Shroff MM, Mueller PR. Tuberculosis from head to toe. Radiographics 2000;20:449-70

\section{How to cite this article:}

Rajesh KM et al (2017) 'A Study Of Ureteric Stricture In Genitourinary Tuber-Culosis', International Journal of Current Advanced Research, 06(05), pp. 3713-3715.

DOI: http://dx.doi.org/10.24327/ijcar.2017.3715.0352 